Review

\title{
Treatment of osteoporosis in men
}

\author{
J.-M. Kaufman ${ }^{\text {a,*}}$, J.-Y. Reginster ${ }^{\mathrm{b}}$, S. Boonen ${ }^{\text {c }}$, M.L. Brandi ${ }^{\mathrm{d}}$, C. Cooper ${ }^{\text {e,f }}$, W. Dere ${ }^{\mathrm{g}}$, J.-P. Devogelaer ${ }^{\mathrm{h}}$,
} A. Diez-Perez ${ }^{\text {i }}$, J.A. Kanis ${ }^{\mathrm{j}}$, E. McCloskey ${ }^{\mathrm{k}}$, B. Mitlak ${ }^{1}$, E. Orwoll ${ }^{\mathrm{m}}$, J.D. Ringe ${ }^{\mathrm{n}}$, G. Weryha ${ }^{\circ}$, R. Rizzoli ${ }^{\mathrm{p}}$

a Department of Endocrinology and Unit for Osteoporosis and Metabolic Bone Diseases, Ghent University Hospital, De pintelaan 185, B9000 Gent, Belgium

${ }^{\mathrm{b}}$ Head Bone and Cartilage Metabolism Unit, CHU Centre-Ville, Liège, Belgium

c Division of Gerontology and Geriatrics and Centre for Musculoskeletal Research, Department of Experimental Medicine, Leuven University, Leuven, Belgium

${ }^{\mathrm{d}}$ Unit of Metabolic Bone Diseases, Department of Internal Medicine, University of Florence, Florence, Italy

e MRC Lifecourse Epidemiology Unit, University of Southampton, Southampton General Hospital, Southampton, UK

${ }^{\mathrm{f}}$ NIHR Musculoskeletal Biomedical Research Unit, Institute of Musculoskeletal Sciences, University of Oxford, Oxford, UK

${ }^{g}$ Amgen, Uxbridge, UK

${ }^{h}$ Arthritis Unit UCL5390, Université Catholique de Louvain, B-1200 Brussels, Belgium

${ }^{\mathrm{i}}$ Hospital del Mar-IMIM-Universitat Autónoma, Barcelona, Spain

j Centre for Metabolic Bone Diseases (WHO Collaborating Centre), University of Sheffield Medical School, Sheffield, UK

${ }^{k}$ Academic Unit of Bone Metabolism, University of Sheffield and NIHR Musculoskeletal Biomedical Research Unit, Sheffield Teaching Hospitals NHS Trust, Sheffield, UK

${ }^{1}$ Lilly Research Labs, Eli Lilly and Company, Indianapolis, USA

${ }^{\mathrm{m}}$ Bone and Mineral Unit, Department of Medicine, Oregon Health \& Sciences University, Portland, OR, USA

${ }^{\mathrm{n}}$ West-German Osteoporosis Center (WOZ) at Klinikum Leverkusen, University of Cologne, Germany

${ }^{\circ}$ Department of Endocrinology, CHU de Nancy, Vandoeuvre, France

p Service of Bone Diseases, Geneva University Hospitals and Faculty of Medicine, 1211 Geneva 14, Switzerland

\section{A R T I C L E I N F O}

\section{Article history:}

Received 18 September 2012

Revised 15 November 2012

Accepted 17 November 2012

Available online 28 November 2012

Edited by: S. Ralston

\section{Keywords:}

Bone mineral density

Fracture risk

Gonadal hormone status

Treatment

T-score

\begin{abstract}
A B S T R A C T
Summary: Aspects of osteoporosis in men, such as screening and identification strategies, definitions of diagnosis and intervention thresholds, and treatment options (both approved and in the pipeline) are discussed. Introduction: Awareness of osteoporosis in men is improving, although it remains under-diagnosed and under-treated. A European Society for Clinical and Economic Aspects of Osteoporosis and Osteoarthritis (ESCEO) workshop was convened to discuss osteoporosis in men and to provide a report by a panel of experts (the authors).

Methods: A debate with an expert panel on preselected topics was conducted.

Results and conclusions: Although additional fracture data are needed to endorse the clinical care of osteoporosis in men, consensus views were reached on diagnostic criteria and intervention thresholds. Empirical data in men display similarities with data acquired in women, despite pathophysiological differences, which may not be clinically relevant. Men should receive treatment at a similar 10-year fracture probability as in women. The design of mixed studies may reduce the lag between comparable treatments for osteoporosis in women becoming available in men.
\end{abstract}

(C) 2012 Elsevier Inc. Open access under CC BY-NC-ND license.

\section{Contents}

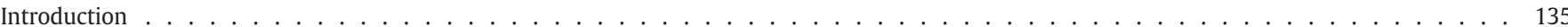

Osteoporosis in men: is it different from postmenopausal osteoporosis? . . . . . . . . . . . . . . . . . . . . . 135

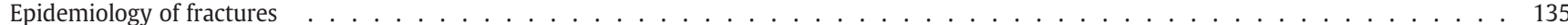

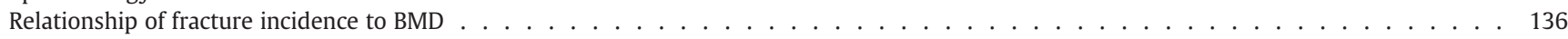

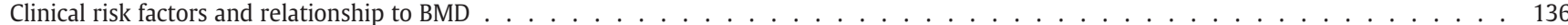

Biochemical markers of bone turnover . . . . . . . . . . . . . . . . . . . . . . . . . 137

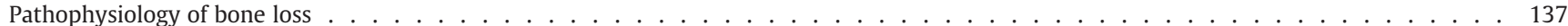

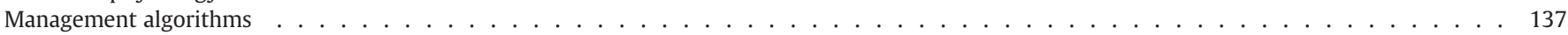

Current European requirements for drugs used in osteoporosis in men . . . . . . . . . . . . . . . . . . . . . 138

Treatment of osteoporosis in men: available agents . . . . . . . . . . . . . . . . . . . . . . . . . . . . . . 138

\footnotetext{
* Corresponding author. Fax: + 3293323817.

E-mail address: Jean.Kaufman@ugent.be (J.-M. Kaufman).
} 
Bisphosphonates . . . . . . . . . . . . . . . . . . . . . . . . . . . . . . . . . . . 138

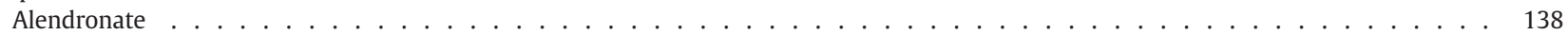

Risedronate . . . . . . . . . . . . . . . . . . . . . . . . . . . . . . . . . . . . . . 138

Zoledronic acid . . . . . . . . . . . . . . . . . . . . . . . . . . . . . . . . . . . . . 139

Teriparatide . . . . . . . . . . . . . . . . . . . . . . . . . . . . . . . . . . . . . . . . . . . . 139

Teriparatide monotherapy . . . . . . . . . . . . . . . . . . . . . . . . . . . . . . . . . 139

Teriparatide combination therapy . . . . . . . . . . . . . . . . . . . . . . . . . . . . . . . . . . . . . . 140

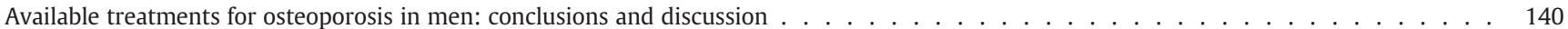

Sex hormones . . . . . . . . . . . . . . . . . . . . . . . . . . . . . . . . . . . . . . . . . . 140

Agents in development for men . . . . . . . . . . . . . . . . . . . . . . . . . . . . . . . . . . . . . . . . . . 140

Therapies in late-stage development . . . . . . . . . . . . . . . . . . . . . . . . . . . . . . . . . . . . . . . . . 140

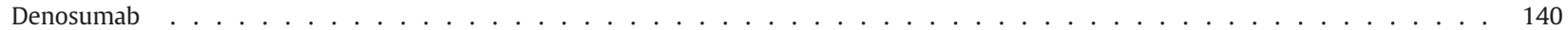

Strontium ranelate . . . . . . . . . . . . . . . . . . . . . . . . . . . . . . . . . . . . . . 141

Odanacatib . . . . . . . . . . . . . . . . . . . . . . . . . . . . . . . . . . . . . . . . 141

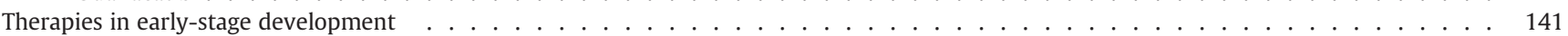

Sclerostin inhibitors . . . . . . . . . . . . . . . . . . . . . . . . . . . . . . . . . . . . . . . . . 141

Calcilytics ..... . . . . . . . . . . . . . . . . . . . . . . . . . . . . . . . . . 141

Drugs in pre-clinical development . . . . . . . . . . . . . . . . . . . . . . . . . . . . . . . . . . . . . . . . . . . . . . . . 141

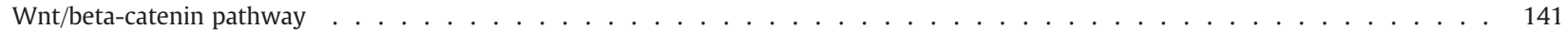

Selective androgen receptor modulators . . . . . . . . . . . . . . . . . . . . . . . . . . . . . . . . . . . . . . 141

Agents in development for men: conclusions and discussion . . . . . . . . . . . . . . . . . . . . . . . . . . . . . . . . . . . . . 141

Overall discussion and conclusions: who should be treated? . . . . . . . . . . . . . . . . . . . . . . . . . . . . . . . . . 141

Conflict of interest . . . . . . . . . . . . . . . . . . . . . . . . . . . . . . . . . . . . . 142

Acknowledgments . . . . . . . . . . . . . . . . . . . . . . . . . . . . . . . . . . . . . . . . . . . 142

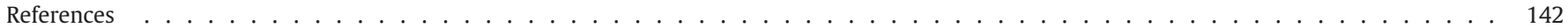

\section{Introduction}

Considerable progress has been made in understanding the pathophysiology and management of osteoporosis, though it remains under-diagnosed and under-treated [1], particularly in men [2]. Osteoporosis is widely considered to be much more prevalent in women, even though approximately $39 \%$ of new osteoporotic fractures estimated to have occurred worldwide in 2000 were in men [3]. Though the average age at which osteoporotic fractures occur in men is approximately 5-10 years later than in women depending on fracture type [4], men have greater morbidity and mortality rates due to hip fractures compared with women [5,6]. There is some lack of awareness among healthcare providers of the need to evaluate men for osteoporosis [7]. Among patients who have sustained a fragility fracture, men and women have a similar relative risk (RR) of sustaining a subsequent fracture $[8,9]$, but men are less likely than women to receive therapy $[10,11]$. Treatment rates are very low in men $(<10 \%)$, even in those with a prior fragility fracture. Moreover, the economic burden of osteoporosis is expected to rise due to ageing populations $[12,13]$.

Progress has been made in the identification of men who should benefit from treatment (e.g. the FRAX management algorithm is applicable to men). However, controversies remain, for instance regarding the criteria by which to define osteoporosis in men on the basis of bone mineral density (BMD). Most information on osteoporosis is in women, and most treatments are developed and approved for use in women. Approved drugs in the US and Europe for osteoporosis treatment in men include bisphosphonates (alendronate, risedronate and zoledronic acid), and teriparatide. Strontium ranelate was recently approved in Europe. Denosumab and other drugs are expected to reach the market in the near future.

This review provides an overview of osteoporosis in men, available treatment options and potential future approaches to treatment.

\section{Osteoporosis in men: is it different from postmenopausal osteoporosis?}

\section{Epidemiology of fractures}

In untreated osteoporosis patients, low BMD is consistently associated with an increase in fracture risk. About $4-6 \%$ of men over the age of
50 years have osteoporosis. Estimates of lifetime fracture risk in men range from 13 to $25 \%$, which is lower than estimates for women, who have a lifetime fracture risk of up to $50 \%$ [14]. The lower lifetime fracture probability arises because of a lower age-specific fracture incidence and shorter life expectancy in men compared to women. Studies on the impact of osteoporosis-related fractures in the United Kingdom have shown that the lifetime risk for hip, spine, and wrist fractures in women is 14,28 , and $13 \%$, respectively, versus 3 , 6 , and $2 \%$ in men [15], although there is variation in reported incidence rates from country to country [16]. In Europe, estimates of the 10-year probability of hip fracture in men and women at the age of 50 range from 0.1 to $0.6 \%$ in men vs. 0.2 to $1.1 \%$ in women, and increase with advancing age [16].

Forearm fractures tend to increase in incidence in white women between the ages of 45 and 60 years, followed by a plateau or more attenuated rise thereafter, whereas rates in men commonly remain low, regardless of increasing age. The incidence of hip fracture increases exponentially with age in both men and women in most regions of the world. Most hip fractures are the result of a fall [17]. Population-based studies of vertebral fracture are difficult to compare, because of a lack of standardised diagnostic methods and criteria. Vertebral fracture prevalence tends to increase with age among men and women, with a steeper gradient among women [18] (Fig. 1). Other fractures associated with low trauma also increase in frequency with age among men, including fractures of the rib, clavicle, proximal humerus and pelvis. They add to the morbidity and mortality burden of osteoporosis in men.

In Caucasians, geographical variations in hip fracture rate in women are mirrored by that in men. However, gender ratios are different in Latin America and Asia, with a blunting of female to male incidence ratios, but the rankings of high to low tend to remain consistent, even outside Europe [19]. Although female and male incidence rates are more approximate for India and China, they are very similar in terms of their rise with advancing age, and remain lower than hip fracture rates observed in most European countries $[20,15,21]$. In a Swedish study, more than twice as many women than men aged $\geq 50$ years were hospitalised for hip fractures [22], and studies have reported higher mortality rates after hip fracture in men than in women. A Canadian study observed $71 \%$ of hip fractures in women and 29\% in men, but in-hospital mortality of women was half that of men (5\% and $10 \%$, respectively) [23]. These 
Men

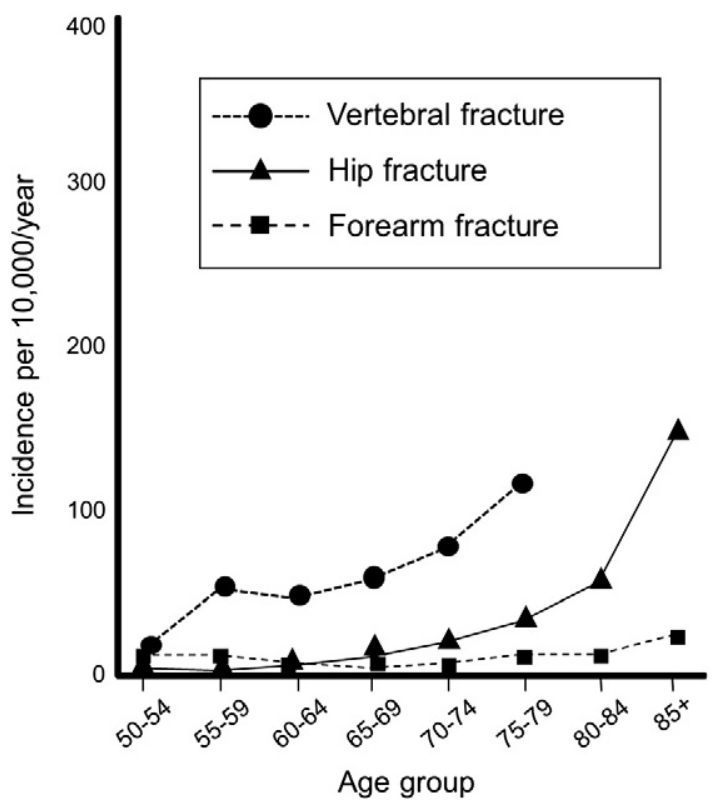

Women

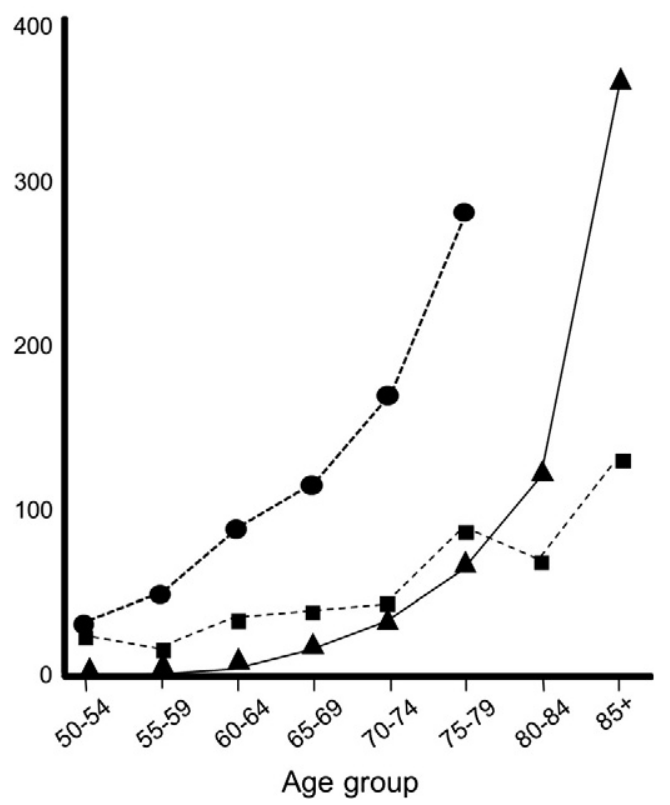

Fig. 1. Osteoporotic fractures in men and women: incidence of osteoporotic fractures in men and women. Adapted from [17].

differences persisted at one year $[4,23]$ and related to pre-fracture health status and post-fracture complications.

Over the last few decades, temporal changes have been reported in the age-specific incidence of fractures in men and women. There does seem to be geographical diversity, particularly in the rate of rise in hip fracture incidence evident towards the end of the 20th century [18]. Hip fracture rates have now stabilised in some Western populations and, in some cases even decreased [24]. In contrast, some studies have suggested that rates are rising in other populations, particularly in Asia $[21,25,26]$.

\section{Relationship of fracture incidence to $B M D$}

The diagnosis of osteoporosis relies on the quantitative assessment of BMD, usually by central dual energy X-ray absorptiometry (DXA) [27]. It was originally defined in postmenopausal women as a BMD value that is 2.5 standard deviations (SD) or more below the young female adult mean. The criteria were later broadened to include men and the femoral neck as the reference site [28] (based on the Third National Health and Nutrition Examination Survey [NHANES III] reference population of women aged 20-29 years) [29].

The use of a common reference range arises from several lines of evidence. A World Health Organization (WHO) systematic review and meta-analysis of data from 12 cohort studies including approximately 39,000 men and women assessed relationship between BMD and fracture risk. The data suggested a consistent increase in the RR of fracture for each SD decrease in femoral neck BMD. The gradient of risk was higher for hip fracture than for all osteoporotic fractures, but was the same in men as in women for both outcomes [8], so that the fracture risk in men and women at any given age was similar for a same absolute BMD value. The same study showed a decreasing gradient of risk for hip fracture with advancing age, but the age-dependency of fracture risk was similar in men and women [8]. The systematic review expressed absolute fracture risk as 10-year probability of hip fracture according to age and BMD T-score and concluded that the age-adjusted hip fracture incidence was identical in men and women of the same age and the same BMD [8].

Because the relationship between BMD and fracture risk changes with age [30], several studies investigating fracture risk in men and women have reached different conclusions [8,31-36]. However, the available studies show that the risk of hip and vertebral fracture is similar in men and women for any given BMD [8,30,35,37-39], supporting the use of a BMD value of 2.5 SD or more below the mean for young adult women for the diagnosis of osteoporosis in men.

\section{Clinical risk factors and relationship to BMD}

The prevalence of individual risk factors for osteoporotic fracture is commonly reported to be different in men compared to women. It is frequently suggested that osteoporosis in men often has secondary causes, the most common being corticosteroid use, excessive alcohol use, and hypogonadism (Table 1). Other causes that are gaining relevance are due to clinical problems related to hormone ablation for prostate cancer (discussed below), highly active anti-retroviral therapy in HIV-infected patients, and immunosuppressive therapy in organ transplanted patients [2]. Both in men and women, age, prior fracture and BMD capture a substantial proportion of fracture risk with further independent contribution of additional risk factors.

According to the MrOS study, which evaluated predictors of non-spine fracture in elderly men after adjusting for BMD, the following clinical risk factors were identified: previous fracture, age, a fall in the past year, use of tricyclic antidepressants, and inability to complete a walking test. The combination of multiple risk factors and low BMD was a powerful indicator of fracture risk. The study found that men who were in the lowest BMD tertile and had three or more clinical risk factors had a 15-fold greater fracture risk than those with no risk factors in the highest BMD tertile [40].

Considering osteoporosis in men as distinct from female osteoporosis might be misconceived. Clinical practice suggests that men are more often diagnosed with secondary osteoporosis, but there are no relevant population-based data to support this notion. It is difficult to distinguish between the multifactorial nature of female $v s$. male osteoporosis. A recently presented subanalysis of the MrOs cohort evaluated secondary causes of osteoporosis in subjects that had low BMD vs. those that did not have low BMD, and most were similar in terms of their risk factors [41]. It is thus not established that secondary osteoporosis really is more common in men. Men may be less likely to be referred for bone densitometry in the absence of specific risk factors for osteoporosis, 
Table 1

Clinical risk factors used for the assessment of fracture probability in men. Adapted from [50].

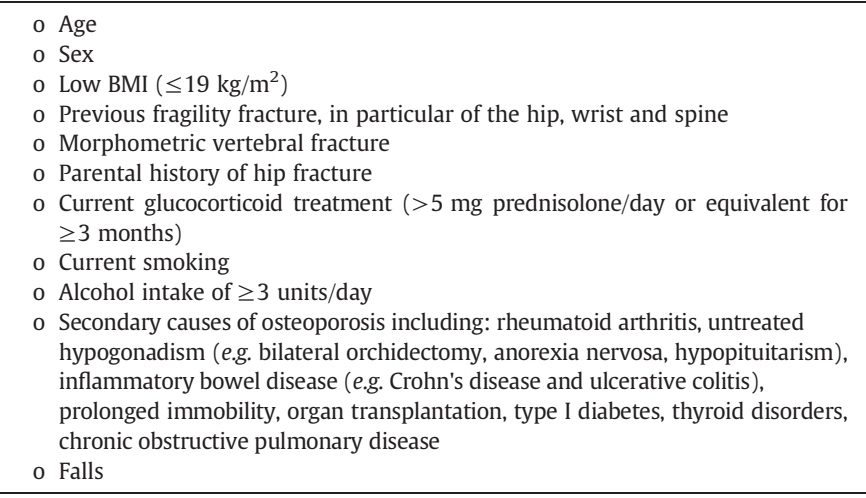

and there may be a general tendency by healthcare practitioners to look for the causes of secondary osteoporosis in men more carefully than in women.

\section{Biochemical markers of bone turnover}

Use of bone formation (serum procollagen type I $\mathrm{N}$ propeptide, sPINP) and bone resorption (serum C-terminal telopeptide of type I collagen, sCTX) markers are recommended by the International Osteoporosis Foundation (IOF) and the International Federation of Clinical Chemistry and Laboratory Medicine (IFCC) as reference analytes for bone turnover markers (BTMs) in clinical studies. Levels of BTMs may predict fracture risk independently from BMD, and may provide data on treatment response and monitoring, although a stronger evidence base is needed.

Conflicting data on the association of BTMs with bone loss and fracture risk in men have been reported. A study in elderly men observed a decreased carboxylated serum osteocalcin to total osteocalcin ratio that was associated with increased subsequent fracture risk [42]. The Dubbo Osteoporosis Study of elderly men reported increased SCTX associated with an increased risk of osteoporotic fractures independent of BMD [43]. Finally, the MrOS cohort demonstrated that biochemical markers in men were predictive of bone loss in a similar manner as in women. Hip and non-spine fractures were associated with increased sPINP and sCTX, but the association no longer held true after adjusting for hip BMD [44]. On the other hand, the MINOS study found that serum concentrations of BTMs were not predictive of fractures [45]. The question of whether BTMs are predictive of accelerated bone loss or fractures in the clinical management of osteoporosis in men remains unanswered. The adoption of international reference standards would help to clarify uncertainties on their clinical use [46].

\section{Pathophysiology of bone loss}

Men have larger bones compared with women, resulting in greater bone strength. With age, bone size may increase in men by periosteal apposition more than in women, thus further increasing the sex difference in bone size (reviewed in [6]). One of the most noteworthy differences between male and female osteoporosis concerns bone microarchitecture. The patterns of bone loss in men seem to be different from those in women. Earlier trabecular loss was measured in men, with cortical loss starting after the age of 50 years, possibly linked to gonadal steroid decline (sex steroids are further discussed below) [7,47]. A deficiency in oestrogen or testosterone may be a unifying factor in the pathophysiology of the disease.

Men have a higher trabecular bone volume/tissue volume, which declines at a similar rate to women. Peripheral quantitative computed tomography (CT) demonstrated that men seem to show a relative preservation of trabecular number, but more trabecular thinning $[7,6]$, presumed to be secondary to reduced bone formation and correlated with indices of reduced bone formation.

\section{Management algorithms}

FRAX is a computer-based algorithm (http://www.shef.ac.uk/FRAX) launched in 2008. It calculates fracture probability from clinical risk factors (Table 1) and patient characteristics (age, weight, height, etc.) in both men and women. The output of FRAX is the 10-year probability of a hip fracture and of a major osteoporotic fracture (hip, clinical spine, humerus or wrist fracture) [48,49]. As is the case for women, there is presently no generally accepted algorithm for the management of osteoporosis in men [50], although FRAX is being increasingly incorporated into practice guidelines. An example for the UK is provided in Table 2.

Before the advent of FRAX, management algorithms for men were very similar to those used in postmenopausal women. In the UK, in the event of a previous fracture, a DXA would be performed or treatment would be considered in the absence of a BMD measurement. In the absence of a previous fracture, but if other clinical risk factors are present (Table 1), a DXA should be performed, and the subject recommended for treatment if their T-score was below -2.5 SD [51]. In other countries, other T-score thresholds have been used [2]. Although risks that justify treatment vary on a national basis, treatment is widely recommended in individuals with a prior history of fragility fracture [50].

Whereas the diagnosis of osteoporosis centres on the assessment of BMD at the femoral neck using DXA, other sites and validated techniques can be used for fracture prediction. The FRAX clinical risk factors contribute to fracture risk independently of BMD. The use of these risk factors in conjunction with BMD improves sensitivity of fracture prediction without adverse effects on specificity [52]. Thus, the FRAX algorithm may significantly impact clinical practice because it helps identify individuals at increased risk of fracture, while avoiding unnecessarily treating patients at low fracture risk.

Table 2

Example of management algorithm for the treatment of men in the UK. Adapted from [49].

Men with a prior fragility fracture should be referred for BMD assessment.

Men aged $\geq 50$ years with clinical risk factors should have fracture probability assessed using the FRAX tool without measurement of BMD.

Individuals with probabilities of a major osteoporotic fracture below the lower predefined assessment threshold can be reassured (range of probabilities for BMD testing according to age, see below). Assessments are recommended every five years or less depending on the clinical context.

Individuals with probabilities of a major osteoporotic fracture above the upper predefined assessment threshold (see below) or with probabilities of a hip fracture above the upper limit can be treated without a prior BMD evaluation.

Individuals with probabilities of a major osteoporotic fracture within the limits of the assessment thresholds and with probabilities of a hip fracture below the limit should have a BMD test and probabilities recomputed. If probabilities exceed the treatment threshold, intervention should be considered. Where probabilities fall below the treatment threshold, assessments are recommended every five years or less depending on the clinical context.

Predefined range of 10-year major fracture probabilities for BMD testing and intervention threshold by age:

$\begin{array}{llll}\text { Age (years) } & \text { Lower limit } & \text { Upper limit } & \text { Intervention threshold } \\ 50 & 5.7 & 9 & 7.5 \\ 55 & 7.5 & 12 & 10 \\ 60 & 10 & 14 & 12.5 \\ 65 & 14 & 20 & 15 \\ 70 & 11 & 25 & 20 \\ 75 & 14 & 29 & 25 \\ 80 & 18 & 34 & 30\end{array}$




\section{Current European requirements for drugs used in osteoporosis in men}

Treatment of osteoporosis in men at increased risk of fracture was first included in the latest revision of the European guidelines on the evaluation of medicinal products in the treatment of osteoporosis [53]. Previous guidelines were only for use in postmenopausal women. The guidelines state that, for women, an effect in reducing fracture risk must be demonstrated on both spinal and non-spinal fractures in a randomised, double-blind, placebo-controlled primary pivotal study with a minimum duration of two years to be conducted either in women with a BMD T-score below - 2.5 SD or in women with prevalent fracture. For women to be included in a trial, a 10-year fracture probability range of $15-20 \%$ for spine, $5-7.5 \%$ for hip and $10-15 \%$ for major non-vertebral fractures is suggested as a clinically relevant and suitable inclusion criterion [53]. Of note, US guidance is slightly different (reviewed in [54]). In future, since the advent of the FRAX approach, studies may recruit patients with an increased 10-year probability of fracture, without distinguishing between prevention and treatment. Therefore, patients with various BMD values (including osteopenia) may be included in studies, provided their 10 -year probability of fracture is increased. The main relevant issues arising from the revised guideline are summarised below:

- In the case of a new drug that has not previously been investigated in women, a two-year placebo-controlled study investigating fracture incidence as the primary endpoint is required to develop drugs for the treatment of osteoporosis in men at increased risk of fracture. Most compounds to treat osteoporosis in men have been developed in females. If a chemical entity has already shown efficacy (reduced fracture incidence) in women, a separate bridging study (vs. placebo in males) of the same drug (same formulation, dose and route of administration) may be carried out, provided that the duration is at least one year, and that BMD at the lumbar spine is the primary endpoint. Baseline fracture risk in the male population should be similar to the fracture risk of the women included in the pivotal study. Finally, the magnitude of BMD changes observed vs. placebo in males should be similar to that observed in postmenopausal women.

- In the majority of bridging trials that have been performed in men, the risk profile of the included study population did not match the fracture risk level in the pivotal trials in postmenopausal women. Moreover, since men with osteoporosis now have access to different treatment modalities, it may not be ethical to include men with high fracture risk in a placebo-controlled bridging study. Because more recent phase III studies have included women at lower risk than traditional studies, the data from these studies are more likely to provide a suitable basis for bridging to a male population with a lower risk (to avoid bridging from a high-risk female population to a lower-risk male population).

\section{Treatment of osteoporosis in men: available agents}

\section{Bisphosphonates}

Bisphosphonates inhibit osteoclastic bone resorption and are the most widely used drugs in male osteoporosis. Studies of male osteoporosis include the evaluation of alendronate, risedronate, and zoledronic acid, as summarised below (Table 3 ). These agents are indicated to increase bone mass in men with osteoporosis.

\section{Alendronate}

In a two-year double-blind study, Orwoll et al. investigated $10 \mathrm{mg}$ /day of alendronate or placebo in $241 \mathrm{men}$ with osteoporosis aged 31-87 years (mean age 63 years). The study included men with femoral neck BMD at least 2 SD and lumbar spine BMD at least 1 SD below the male reference, or with femoral neck BMD at least 1 SD below male reference and at least one vertebral deformity or a history of an osteoporotic fracture. Half of the study population had established osteoporosis. At baseline, approximately 50\% of patients had already sustained vertebral fractures [55].

Alendronate-treated men showed a similar increase in BMD as previously reported in postmenopausal women [56,57]. Lumbar spine BMD increased by $7.1 \pm 0.3 \%$, whereas femoral neck BMD increased by $2.5 \pm 0.4 \%$ [55]. The changes in BMD with alendronate were not affected by circulating levels of sex steroids (testosterone and oestradiol). Therefore, treatment and anti-fracture efficacy of bisphosphonate may potentially be similar in hypogonadal men and eugonadal men. In less extreme circumstances, this observation remains relevant in normal men whose testosterone levels decrease with ageing [58].

The alendronate study for the treatment of osteoporosis in men was a BMD endpoint study, and as such was not powered to determine anti-fracture efficacy. However, radiographic vertebral, clinical vertebral and non-vertebral fracture risks were numerically reduced in alendronate-treated men, without achieving a level of significance. The effect of alendronate on the change in height was significant. Men in the placebo group lost $2.4 \mathrm{~mm}$ in height, compared with $0.6 \mathrm{~mm}$ in the alendronate-treated men $(p=0.02)$. These data, although not conclusive, are consistent with anti-fracture efficacy [55].

\section{Risedronate}

A similar two-year BMD endpoint study was performed with risedronate $35 \mathrm{mg}$ once a week in 284 men with osteoporosis aged 36-84 years (mean age 60) [59]. Men with a femoral neck BMD of at least 2 SD and lumbar spine BMD at least 1 SD below male reference

Table 3

Overview of studies in men with osteoporosis (approved agents).

\begin{tabular}{|c|c|c|c|c|}
\hline Agent & $\mathrm{N}$ & Study duration & Main efficacy outcomes & Reference \\
\hline $\begin{array}{l}\text { Alendronate } \\
10 \mathrm{mg} / \text { day }\end{array}$ & 241 & 2 years & o LS-BMD increased by $7.1 \pm 0.3 \%$, and FN-BMD increased by $2.5 \pm 0.4 \%$. & {$[55]$} \\
\hline $\begin{array}{l}\text { Risedronate } \\
35 \mathrm{mg} \text { qw }\end{array}$ & 284 & 2 years & $\begin{array}{l}\text { o Significant increase from baseline to endpoint in LS-BMD vs. placebo } \\
(4.5 \%, 95 \% \mathrm{CI}: 3.5-5.6, p<0.001) \text {. } \\
\text { o Significant increases in hip BMD vs. placebo. }\end{array}$ & [59] \\
\hline $\begin{array}{l}\text { Zoledronic acid } \\
5 \mathrm{mg} \text { once a year }\end{array}$ & 1199 & 2 years & $\begin{array}{l}\text { o Morphometric VF results showed a } 67 \% \text { reduction in risk of new VF. } \\
\text { o LS-BMD increased from } 4.7 \% \text { at six months to } 6.1 \% \text { at two years. } \\
\text { o Significant increases in LS-BMD vs. placebo. }\end{array}$ & [65] \\
\hline $\begin{array}{l}\text { Teriparatide } \\
20 \text { or } 40 \mathrm{mcg} / \text { day }\end{array}$ & 437 & $\begin{array}{l}\text { Premature termination } \\
\text { (median total exposure } 11 \text { months) }\end{array}$ & $\begin{array}{l}\text { o LS-BMD increased by } 5.9 \%(20 \mathrm{mcg}) \text { and } 9.0 \% \text { ( } 40 \mathrm{mcg} \text { ) above baseline } \\
(p<0.001 \mathrm{vs} \text {. placebo for both). } \\
\text { o FN-BMD increased by } 1.5 \%(20 \mathrm{mcg}, p=0.029) \text { and } 2.9 \% \text { ( } 40 \mathrm{mcg}, p<0.001) \text {. }\end{array}$ & [69] \\
\hline $\begin{array}{l}\text { Strontium ranelate } \\
2 \mathrm{~g} / \mathrm{day}\end{array}$ & 261 & 2 years ( 1 year to main analysis) & $\begin{array}{l}\text { o LS-BMD increase at } 1 \text { year similar to that previously observed in core studies in } \\
\text { postmenopausal women. } \\
\text { o Significant increase at the femoral neck. }\end{array}$ & [97] \\
\hline
\end{tabular}

BMD, bone mineral density; CI, confidence interval; FN, femoral neck; LS, lumbar spine; qw, once a week; VF, vertebral fracture. 
values or a femoral neck BMD at least 1 SD and lumbar spine BMD at least 2.5 SD below male reference values were included. At baseline, $35 \%$ and $34 \%$ of patients had prevalent vertebral fractures in the placebo and risedronate groups, respectively [59].

The study reported a significant increase from baseline to endpoint in lumbar spine BMD compared with placebo (4.5\%, 95\% CI: 3.5-5.6, $p<0.001)$. Significant increases in hip BMD were also observed compared with placebo. A 40\% reduction in type 1 cross-linked N-telopeptide (NTX) was observed in risedronate-treated men, again similar to reports in postmenopausal women [60]. This study also showed that the effects on bone density and on NTX were not affected by circulating testosterone. The trial was not designed as a fracture-endpoint study; the number of fractures was small, as expected, because of the sample size and the study design. No statistically significant difference between treatment groups for the overall incidence of vertebral fractures or clinical fractures was observed. The cumulative incidence of clinical fractures was $7.7 \%$ in men on placebo vs. $4.9 \%$ in risedronate-treated men (RR 0.69 [0.25-1.93]). The positive effects of risedronate in men with osteoporosis were confirmed in an open-label, prospective, match-control trial [61].

\section{Zoledronic acid}

Approval of zoledronic acid for use in men was based on findings from the HORIZON Recurrent Fracture Trial (RFT), a study involving 508 men and 1619 women with a recent low trauma hip fracture that had been surgically repaired [62]. In this study, zoledronic acid (as an annual $5 \mathrm{mg}$ infusion) showed a 35\% reduced risk of new clinical fractures in the overall population compared with placebo, and no significant treatment-by-gender interaction was observed. More recently, an analysis of the subset of men participating in the HORIZON-RFT confirmed that the increase in BMD in men was statistically similar to that observed in women with recent hip fracture [63]. Low numbers of clinical fractures were observed in men in the HORIZON-RFT (16 [7.45\%] and 20 [8.7\%] for zoledronic acid and placebo, respectively), with no significant difference between the treatment groups. This lack of a statistically significant fracture reduction was expected, as the gender-based subset analysis was powered for a BMD endpoint and not for anti-fracture efficacy. In line with these findings, a head-to-head trial comparing once-yearly zoledronic acid with daily oral alendronate in men with low BMD also showed the expected effects of zoledronic acid on bone density and bone turnover [64].

Most recently, a fracture endpoint study in male osteoporosis investigated once-yearly intravenous (iv) zoledronic acid treatment in a randomised, multi-centre, double-blind, placebo-controlled, two year study. The primary efficacy endpoint was the reduction in vertebral fracture risk at the two-year endpoint of the trial. In all, 1199 patients were randomised to an annual infusion of either zoledronic acid $5 \mathrm{mg}$ or placebo, and supplemented with calcium 1000-1500 mg and vitamin D 800-1200 mg/day. Patient inclusion and exclusion criteria were similar to previous bisphosphonate studies, in that men aged 50-85 years (mean age 65.8) with primary osteoporosis or secondary osteoporosis due to hypogonadism were included. Of note, this was a low-risk population compared to studies investigating postmenopausal women on zoledronic acid, because male reference values were used. The results of the study have recently been fully published [65]. Overall, the findings showed changes in surrogate outcomes (bone density and bone turnover) in line with those reported in pivotal trials of postmenopausal women [66]. Vertebral fracture risk reductions were similar in magnitude to those previously reported with iv zoledronic acid in postmenopausal osteoporosis.

\section{Teriparatide}

Teriparatide is classified as a parathyroid hormone (PTH) analogue that has an identical sequence to the $34 \mathrm{~N}$-terminal amino acids (the biologically active region) of the 84-amino acid human parathyroid hormone. It is indicated to increase bone mass in men with primary or hypogonadal osteoporosis at high risk for fracture and in the treatment of osteoporosis associated with sustained systemic glucocorticoid therapy in men at high risk of fracture.

\section{Teriparatide monotherapy}

Initial indications that teriparatide was useful in male osteoporosis were published in the 1980s [67,68]. A placebo-controlled, double-blind trial subsequently led to its approval for the treatment of men in the US [69] (Table 3). This bridging study included 437 men with low BMD (hip or spine T-score $<-2.0 \mathrm{SD}$ ) without secondary causes of osteoporosis. Patients were randomised into three groups, and either received once daily subcutaneous 20 or 40 mcg teriparatide, or placebo. The patients were supplemented with calcium (1000 $\mathrm{mg} /$ day) and vitamin D (400 to $1200 \mathrm{IU}$ ) (continued during the subsequent follow-up observation phase). The study's primary endpoint was lumbar spine BMD. It was prematurely terminated (median total exposure 11 months), because osteosarcomas developed in rats during toxicological evaluation. This observation was, however, not considered predictive of an increased risk for humans treated for relatively short periods [70]. Baseline values showed that the study population was relatively young (58-59 years old), with relatively elevated spine BMD and low risk T-scores. About $40 \%$ of participants had vertebral fractures and half had low free testosterone values.

The patterns of biochemical marker changes in response to teriparatide were typical (dose-dependent increases in bone formation and resorption markers) and very closely mirrored similar data in women, albeit with a lower magnitude [69]. The changes in BMD were also very similar to those previously reported in women [71]. Both teriparatide doses led to the expected changes in spine, total hip and femoral neck BMD. When BMD responses to $20 \mathrm{mcg}$ of teriparatide are compared in men and women, the absolute change in BMD is similar. Analyses showed consistent responses across the risk groups usually seen in male osteoporosis, in that responses did not differ according to baseline BMD, age, gonadal status, previous fracture status, smoking or alcohol consumption [69].

In an 18 -month follow-up study, about $80 \%$ of patients agreed to be observed without receiving study medication, but with the option to undertake other therapies [72]. After treatment discontinuation, BMD declined in both teriparatide treatment groups, particularly at the lumbar spine [72]. There was no difference in the rate of BMD decline as a function of testosterone concentrations [72]. From the original treatment trial baseline to the 18 months visit of the follow-up study, there was a lower incidence of moderate and severe fractures, in the combined 20 and $40 \mathrm{mcg}$ teriparatide groups than in the placebo group $(p=0.01)$ [72]. However, these data should be interpreted with caution, because approximately $22 \%$ of the men reported the use of a bisphosphonate at some point during the follow-up study. Again, the point estimates for the reduction in vertebral fracture risk in men were essentially the same as in women [73], despite the smaller study size.

Of interest, Leder et al. investigated the effects of teriparatide treatment and discontinuation [74] in a small study involving 14 postmenopausal women and 17 eugonadal men with osteoporosis, aged 46-85 years, with lumbar spine or femoral neck T-scores $<-2$ SD. Daily teriparatide $(37 \mathrm{mcg}$ ) was administered subcutaneously for 24 months, followed by 12 months off therapy. The study observed that, following teriparatide discontinuation, the rate of BMD decline was greater in women than in men, possibly highlighting a difference in teriparatide response or in the drivers of BMD maintenance in men and women. The $5.9 \%$ female to male difference in trabecular BMD loss was statistically significant ( $p=0.037 ; 95 \% \mathrm{CI}, 11.2-0.4$ ), but the difference in absolute trabecular BMD loss was not. The mechanisms underlying this potential relative resistance to post-teriparatide bone loss in men are unclear. This observation requires confirmation in larger studies and in men and women receiving the approved teriparatide dose of $20 \mathrm{mcg} / \mathrm{day}$. One concern is that teriparatide appears to require continued administration for a sustained biological effect, unlike 
bisphosphonates that have persistent effects on bone resorption many months after drug exposure [75-77]. However, Lindsay et al. also reported that women with postmenopausal osteoporosis showed sustained vertebral fracture risk reduction after withdrawal of teriparatide (at least 18 months) [73].

Finally, a post-marketing study on the use of teriparatide in the US, derived from the Direct Assessment of Nonvertebral Fracture in the Community Experience (DANCE) study, described gender differences for initiating teriparatide therapy. The drug was used more often in women, based on general frailty, low body mass and an inadequate response or intolerance to previous therapy. Chronic glucocorticoid therapy was the reason most often given by investigators for initiating therapy in men, and more often used as an indicator for therapy in men, illustrating the possibility that at least in the US, physicians view teriparatide use somewhat differently in men vs. women [78], and providing further evidence from a clinical practice setting that male osteoporosis is under-diagnosed and likely under-treated.

\section{Teriparatide combination therapy}

A study randomly assigned 83 men with low BMD to receive $10 \mathrm{mg} /$ day alendronate, $40 \mathrm{mcg} /$ day teriparatide subcutaneously, or both. Alendronate was administered for 30 months, and teriparatide was started after six months. Lumbar spine and femoral neck BMD increased significantly more in men on teriparatide monotherapy compared with the other groups. Changes in serum BTM were significantly greater in the teriparatide group than in the alendronate group or the combination therapy group $(p<0.001)$. As with BMD, a second study showed that alendronate impaired the action of teriparatide to increase bone turnover in men $[79,80]$. Previous studies in postmenopausal women also suggested that concomitant alendronate and PTH (1-84) reduced the anabolic effects of PTH [75,81]. These data may influence therapeutic choices after PTH discontinuation, because its use is limited to a maximum of two years [75].

Although these studies suggested that combination of teriparatide and bisphosphonates had no additive effect because alendronate diminished the teriparatide effect, zoledronic acid was shown not to block the anabolic effect of PTH. In a one-year partial double-blind randomised study of 412 postmenopausal women, Cosman et al. concluded that, while teriparatide increased spine BMD more than zoledronic acid, and zoledronic acid increased hip BMD more than teriparatide, combination therapy provided the best BMD improvement, both in spine and hip BMD [82].

\section{Available treatments for osteoporosis in men: conclusions and discussion}

The treatment response to oral bisphosphonates in male osteoporosis is similar to that observed in postmenopausal osteoporosis, in terms of bone density and bone remodelling. To date, conclusive anti-fracture evidence with alendronate and risedronate is unavailable in men, but fracture reductions are very consistent. With iv zoledronic acid, a recent report of fracture endpoint data in osteoporotic men indicates that zoledronic acid anti-fracture efficacy in men mirrored that observed in women. The approaches developed to treat and identify women at high risk (e.g. the FRAX approach) are likely to be equally useful in men.

Teriparatide studies concluded that the changes in biochemical markers, BMD, and vertebral fracture risk in response to $20 \mathrm{mcg}$ teriparatide in men were essentially the same as in women. Studies have suggested that combination of teriparatide and alendronate diminished the teriparatide effect, but zoledronic acid was shown not to block the anabolic effect of PTH in women. Teriparatide appears to be an effective therapy in men with osteoporosis, yet maintenance of its effects after treatment cessation is not fully understood and may require subsequent initiation of bisphosphonate treatment.

\section{Sex hormones}

Several agents are known to have a positive effect on BMD in the extreme event of acute hypogonadism due to chemical castration, including bisphosphonates and denosumab (discussed below) [83,84]. It seems reasonable to use these agents to avoid bone loss in men receiving androgen deprivation therapy, particularly when baseline BMD is low or if other fracture risk factors are present.

Testosterone prevents bone loss and may increase bone mass in hypogonadal men, although there is little available long-term data and no fracture data. Despite testosterone's beneficial effects on the skeleton when initiated in the broader context of androgen replacement in established hypogonadism, it is not indicated for osteoporosis treatment as such [9]. A hypogonadal man with a high risk of fracture should receive classical osteoporosis medication [58], regardless of whether testosterone is being initiated on the basis of current hypogonadism treatment guidelines.

An important point concerns oestradiol, which may be more related to fracture than testosterone, and raises the question of oestradiol assay sensitivity and standardisation. Low oestradiol levels were associated with high bone remodelling and bone loss, whereas no such relationship was found for testosterone $[85,86]$, and were also associated with increased fracture incidence [87]. In the MrOs cohort, sex steroids were measured using mass spectrometry in elderly men. Serum-free oestradiol but not testosterone, was independently associated with fracture risk [88]. In clinical practice, the potential implication is that measurement of serum sex steroid contribution could become standardised. These data provide a rationale for assessing the use of selective oestrogen receptor modulators (SERMs) in men. Although oestrogen or SERMs are currently not approved for use in men, raloxifene reduces bone turnover in men with low endogenous oestradiol levels $[89,90]$ and increases BMD in prostate cancer patients undergoing gonadal suppression therapy [91], with the caveat that raloxifene increases bone turnover in men with serum oestradiol levels above the population median.

\section{Agents in development for men}

A number of drugs with anti-fracture efficacy in postmenopausal women are available and are likely to be applicable in men, provided that bridging studies are carried out. An overview of drugs in development demonstrates that the most promising novel treatments include combination treatments (as outlined above with bisphosphonates and teriparatide), denosumab, strontium ranelate, odanacatib (a specific inhibitor of the osteoclast protease cathepsin $\mathrm{K}$ ), antibodies against endogenous inhibitors of bone formation sclerostin and dickkopf-1 (Dkk-1), and saracatinib (Src inhibitor), a cancer drug which has not yet been applied in osteoporosis (reviewed in [92]).

\section{Therapies in late-stage development}

\section{Denosumab}

The anti-resorptive denosumab is a monoclonal antibody that binds and neutralises the activity of human receptor activator of nuclear factor- $\kappa \mathrm{B}$ ligand (RANKL), a key osteoclast cytokine, similarly to endogenous osteoprotegerin. This agent is indicated to increase bone mass in men at high risk for fracture receiving androgen deprivation therapy for nonmetastatic prostate cancer. Denosumab has been shown to increase BMD and reduce fractures in postmenopausal women with osteoporosis [93] and in men with prostate cancer on hormone ablation therapy. In a double-blind, randomised, multi-centre study, denosumab was investigated in men receiving androgen-deprivation therapy for nonmetastatic prostate cancer. Patients received $60 \mathrm{mg}$ denosumab subcutaneously every six months or placebo (734 patients in each group). At 24 months, lumbar spine BMD increased by $5.6 \%$ in the denosumab group as compared with a loss of $1.0 \%$ in the placebo group $(p<0.001)$. The difference was significant as early as one month. Significant BMD increases were 
also reported at the total hip, femoral neck, and distal third of the radius at all time points. At 36 months, denosumab-treated patients had a significantly decreased incidence of new vertebral fractures (1.5\%,vs. $3.9 \%$ with placebo) (RR, $0.38 ; 95 \% \mathrm{CI}, 0.19-0.78 ; p=0.006)$, and markers of bone turnover were significantly decreased compared with placebo $(p<0.001)$ [84]. The efficacy and safety of denosumab in men with low bone mass at risk of fracture is being further evaluated in the ongoing phase III denosumab vs. placebo ADAMO trial [94].

\section{Strontium ranelate}

Strontium ranelate is an alternative orally active drug with opposite effects on bone resorption and formation, that has been demonstrated to significantly reduce vertebral and non-vertebral fracture risk in women with postmenopausal osteoporosis [95,96]. At time of submission of this review, Strontium ranelate was recently approved for treatment of osteoporosis in men, but the complete results of the main study in men have not yet been published. A two-year, controlled, double-blind bridging study has been performed in osteoporotic men. The objective was to study men with a similar risk profile as the postmenopausal women previously included in the pivotal phase 3 trials, therefore the BMD inclusion criterion was below a same absolute BMD threshold value as in the studies in women. In a preliminary communication of the results at one year (main study analysis), the authors reported that a same dosage of strontium ranelate with calcium and vitamin D supplementation resulted in similar strontium blood levels and a similar significant BMD gain at the spine and hip in osteoporotic men compared with osteoporotic postmenopausal women [97].

Of note, an open-label, prospective, controlled, BMD endpoint 12-month trial in male osteoporosis patients compared strontium ranelate $2 \mathrm{~g} / \mathrm{day}(\mathrm{n}=76) v$ s. alendronate $70 \mathrm{mg} /$ week, an agent already approved for male osteoporosis. Mean increases in lumbar spine and total hip BMD were greater with strontium ranelate compared with alendronate [98], although the increment in BMD is partly dependent on a treatment-induced artefact. These strontium ranelate data support the increases in BMD observed in the recent core bridging study.

\section{Odanacatib}

Odanacatib inhibits cathepsin-K, a protease that plays an important part in osteoclast function. A phase III odanacatib trial in men with osteoporosis is ongoing (NCT01120600). In postmenopausal women, the effect of odanacatib on biochemical markers of bone turnover (sCTX, bALP) and on change in lumbar spine and femoral neck BMD ( $v$ s. baseline) was promising at 24 and 36 months [99,100]. Femoral neck BMD decreased after odanacatib discontinuation, although it remained above baseline levels [100].

\section{Therapies in early-stage development}

\section{Sclerostin inhibitors}

Therapies currently in phase II development include sclerostin inhibitors [101]. Data obtained in sclerostin knock-out (KO) mice have shown that these have high bone mass and normal bone morphology, but with increased trabecular and cortical bone volume. Other than the bone phenotype, no additional biologically significant differences were observed between wild-type and KO mice. Based on micro CT imaging, female $\mathrm{KO}$ mice appeared to have increased bone volume compared with males [102]. Anti-sclerostin antibody was also shown to increase markers of bone formation and BMD in healthy men and postmenopausal women [103].

\section{Calcilytics}

The stimulation of spontaneous endogenous PTH secretion, using calcium receptor agonists that tend to reduce serum calcium (calcilytics), has been proposed as an alternative approach to teriparatide administration. Examples of such compounds include ronalcaleret and JTT-305. Ronalcaleret had no effect on BMD, possibly because of a prolonged stimulation of PTH secretion [104]. JTT-305 was tested over three months in 154 postmenopausal osteoporotic women randomised to three groups: placebo $(n=51), 10 \mathrm{mg} /$ day $(n=50)$ and $20 \mathrm{mg} /$ day $(n=53)$. Some differences in spine BMD and effects on P1NP and CTX markers, were found [105]. Interesting data on newer calcilytic drugs may emerge in the near future [92].

\section{Drugs in pre-clinical development}

\section{Wnt/beta-catenin pathway}

Advances in the molecular understanding of processes involved in the bone-anabolic pathway have highlighted the canonical Wnt/beta-catenin pathway as a key regulator of bone formation [106], which is negatively regulated by Wnt inhibitors such as Dkk-1 and sclerostin [107]. The Wnt pathway is composed of multiple potential drug targets involved in its activation (19 Wnts, 10 Frizzled, 3 LRPs) or inhibition (4 Sfrp, Dkk-1, sclerostin). Some components such as catenin, Rho, or PKC also interact with multiple pathways that are not specific for bone, which complicates matters in the context of targeted therapy. Importantly, interference with Wnt inhibitory factor 1 (WIF1) is associated with a potential risk of neoplastic development (osteosarcoma) [108]. Moreover, the reversibility or duration of the effect is not fully established. If therapy is stopped once good bone forming activity has been achieved, it is not clear whether this effect should be maintained with the administration of bone resorption inhibitors.

\section{Selective androgen receptor modulators}

Selective androgen receptor modulators (SARMs) have been shown to improve muscle strength and body composition, and to prevent bone loss in orchidectomised rats [109]. These agents display tissue-selective pharmacologic activity and may have an advantage over steroidal androgen therapy. Yarrow et al. demonstrated that trenbolone had advantages over testosterone in orchidectomised rats, supporting the need for future studies examining its potential in androgen replacement therapy [110]. Overall, these data do not display a very high magnitude of effect on bone strength. Moreover, the effects of respective SARMs on endogenous oestrogen levels and on the skeleton may diminish the clinical potential of these agents [9].

\section{Agents in development for men: conclusions and discussion}

Potential drugs for the treatment of osteoporosis in men include two broad categories, either of bone resorption inhibitors or of bone formation stimulators, as reviewed elsewhere [92]. Several additional agents are expected to be approved for the treatment of osteoporosis in men in the near future. Strontium ranelate has recently been approved in Europe for treatment of osteoporosis in men, but publication of complete results of the core study is still awaited. Denosumab is approved for use in men receiving androgen deprivation therapy for nonmetastatic prostate cancer who are at high risk of fracture. Data on the effect of denosumab in men with low bone mass at risk of fracture are also on the horizon. Other promising therapies at different stages of development include odanacatib, sclerostin inhibitors, or calcilytics.

\section{Overall discussion and conclusions: who should be treated?}

There is general agreement on the diagnosis of osteoporosis in men. In terms of assessment algorithms, different approaches have been used, either a traditional approach or a fracture probability-based approach, as is the case in the UK (Table 2). FRAX is, however, increasingly used in guidelines as they undergo revision.

The treatment algorithm and clinical guidance, which this panel wishes to support, aim to treat men at a similar 10-year fracture risk as in women, because the morbidity and mortality associated with major osteoporotic fractures in men are substantial. Available evidence suggests that treatment algorithms in women are also applicable to 
men. In practice, this is likely to involve the use of FRAX and clinical risk factors (Table 1). The use of fixed intervention thresholds is viewed as counter-intuitive to current practice, because the risk is to exclude too many younger patients and, conversely, to include too many older patients above a threshold value.

The available level of evidence that treatment decreases the risk of fracture in men is lower than for women. As such, the US Endocrine Society is of the opinion that there is currently not enough information in men to make a recommendation, because too few fractures have been recorded in men to link BMD changes with anti-fracture efficacy. Additional fracture data are needed to endorse the clinical care of osteoporosis in men. However, this panel believes that this view can be countered, based on available epidemiological and clinical efficacy data in male subjects, which display similarities with data acquired in women, in terms of treatment effects on BMD, biochemical markers of bone turnover, and fracture endpoint, despite the recorded differences in pathophysiology of bone loss and bone microarchitecture. Overall, empirical data from men and women are so similar that differences in morphology may not be clinically relevant.

Despite the wealth of available data from numerous studies in women, the current strategy of drug development for the treatment of osteoporosis in men is such that there is a delay of several years before clinical trial data in men become available. Perhaps the lag between comparable treatments becoming available for female and for male osteoporosis can be reduced. The situation is not unlike coronary artery disease, which was initially thought to be principally a male disease, but for which female treatment was made more rapidly available. A logical conclusion would eventually be to design mixed studies, as recommended by the WHO [111]. From a pragmatic point of view, it is unlikely that drugs for the specific treatment of osteoporosis in men will be developed.

One area of research that deserves more attention is the hormonal and non-hormonal factors influencing bone loss in men. There appears to be potential in measuring serum oestradiol levels, in addition to testosterone levels in men with low BMD. We wish to encourage the development of standardised mass spectroscopy assays for the assessment of sex steroid contribution in male osteoporosis.

Awareness of osteoporosis in men is improving, although it remains under-diagnosed and under-treated. It is important to highlight this population of patients and to define treatment options and intervention strategies, in order to reduce mortality, improve treatment and care, and make sure that treatments reach those who most need it.

\section{Conflict of interest}

J-MK received consulting fees, paid advisory boards, lecture fees and/ or grant support from Amgen, Eli Lilly, Glaxo Smith Kline, Merck Sharp \& Dohme, Novartis, Roche, Sanofi Aventis, Servier and Warner Chilcott. J-YR received consulting fees or paid advisory boards from Amgen, Glaxo Smith Kline, Eli Lilly, Merckle, Negma, Novartis, NPS, Nycomed, Servier, Theramex, UCB and Wyeth, lecture fees from Merck Sharp and Dohme, Eli Lilly, Rottapharm, IBSA, Genevrier, Novartis, Servier, Roche, GlaxoSmithKline, Teijin, Teva, Ebewee Pharma, Zodiac, Analis, Theramex, Nycomed, Novo-Nordisk, Nolver, and grant support from Merck Sharp and Dohme, Eli Lilly, Rottapharm, IBSA, Genevrier, Novartis, Servier, Roche, GlaxoSmithKline, Teijin, Teva, Ebewee Pharma, Zodiac, Analis, Theramex, Nycomed, Novo-Nordisk, Nolver. SB reports institutional research support and consulting fees from Amgen, Novartis and Servier. MLB was consultant and grant recipient from Amgen, Eli Lilly, MSD, Novartis, NPS, Roche and Servier. CP has received honoraria and consulting fees from Amgen, Eli Lilly, Medtronic, Merck, Novartis and Servier. WD is an employee from Amgen and shareholder from Eli Lilly and Amgen. J-PD has received consulting or advisory board fees from Novartis, lecture fees from Amgen, and grant support from Servier, Novartis, and Amgen. ADP was speaker and/or scientific advisor for Amgen, Lilly, Merck Sharp \& Dohme, Novartis and Active Life
Technologies, and received research funding from Amgen. JAK has received consulting fees/research funding from Amgen, Lilly, Servier and Warner-Chilcott. EMcC declares paid advisory boards from Amgen, Medtronic and Tethys, speakers honoraria from Amgen, Bayer, GE Lunar, Glaxo Smith Kline, Hologic, Eli Lilly, Medtronic, Merck, Novartis, Pfizer, Servier, Warner-Chilcott, and research funding from Amgen, Innovus 3i, Eli Lilly, Novartis, and Pfizer. BM is an employee and shareholder from Eli Lilly. EO has received research funding from Eli Lilly, Amgen and Merck. He has been a consultant for Eli Lilly, Merck, Amgen and Wright Medical Technology. JDR gives advice to and lectures for Amgen, Glaxo Smith Kline, Leo Pharma, Merck and Servier. GW declares consulting fees or paid advisory boards from Novartis, lecture fees from Eli Lilly, Servier, Theramex, and clinical trial fees as investigator from Amgen, Eli Lilly, Merck Sharp \& Dohme, Nycomed, Roche, and Servier. RR declares paid advisory boards or speaker bureau for Merck Sharp and Dohme, Eli Lilly, Amgen, Servier and Danone.

\section{Acknowledgments}

We thank P. Belissa-Mathiot for her valuable input to this review. We thank Dr Vanessa Gray-Schopfer, OmniScience SA and Wolters Kluwer Pharma Solutions France who provided medical writing services on behalf of the ESCEO panel. The authors were fully responsible for contents and editorial decisions for this manuscript.

The Alliance for Better Bone Health (Sanofi and Warner Chilcott) provided an unrestricted educational grant to support this publication. The Alliance has had no editorial control over this publication.

\section{References}

[1] Teng GG, Curtis JR, Saag KG. Quality health care gaps in osteoporosis: how can patients, providers, and the health system do a better job? Curr Osteoporos Rep 2009;7:27-34.

[2] Ebeling PR. Clinical practice. Osteoporosis in men. N Engl J Med 2008;358: 1474-82.

[3] Johnell O, Kanis JA. An estimate of the worldwide prevalence and disability associated with osteoporotic fractures. Osteoporos Int 2006;17:1726-33.

[4] Campion JM, Maricic MJ. Osteoporosis in men. Am Fam Physician 2003;67: 1521-6.

[5] Kaufman JM, Goemaere S. Osteoporosis in men. Best Pract Res Clin Endocrino Metab 2008;22:787-812.

[6] Seeman E. Pathogenesis of bone fragility in women and men. Lancet 2002;359: 1841-50.

[7] Khosla S. Update in male osteoporosis. J Clin Endocrinol Metab 2010;95:3-10.

[8] Johnell O, Kanis JA, Oden A, Johansson H, De Laet C, Delmas P, et al. Predictive value of BMD for hip and other fractures. J Bone Miner Res 2005;20:1185-94

[9] Kanis JA, Bianchi G, Bilezikian JP, Kaufman JM, Khosla S, Orwoll E, et al. Towards a diagnostic and therapeutic consensus in male osteoporosis. Osteoporos Int 2011:22:2789-98.

[10] Center JR, Bliuc D, Nguyen TV, Eisman JA. Risk of subsequent fracture after low-trauma fracture in men and women. JAMA 2007;297:387-94.

[11] Curtis JR, McClure LA, Delzell E, Howard VJ, Orwoll E, Saag KG, et al. Populationbased fracture risk assessment and osteoporosis treatment disparities by race and gender. J Gen Intern Med 2009;24:956-62.

[12] Burge R, Dawson-Hughes B, Solomon DH, Wong JB, King A, Tosteson A. Incidence and economic burden of osteoporosis-related fractures in the United States, 2005-2025. J Bone Miner Res 2007;22:465-75.

[13] Ström O, Borgström F, Kanis JA, Compston J, Cooper C, McCloskey EV, et al. Osteoporosis; Burden, health care provision and opportunities in the EU. A report prepared in collaboration with the International Osteoporosis Foundation (IOF) and the European Federation of Pharmaceutical Industry Associations (EFPIA). Arch Osteoporos 2011 http://dx.doi.org/10.1007/s11657-11011-10060-11651.

[14] Bilezikian JP. Osteoporosis in men. J Clin Endocrinol Metab 1999;84:3431-4.

[15] Harvey N, Dennison E, Cooper C. Osteoporosis: impact on health and economics. Nat Rev Rheumatol 2010;6:99-105.

[16] Kanis JA, Johnell O, De Laet C, Jonsson B, Oden A, Ogelsby AK. International variations in hip fracture probabilities: implications for risk assessment. J Bone Miner Res 2002;17:1237-44.

[17] Sambrook P, Cooper C. Osteoporosis. Lancet 2006;367:2010-8.

[18] Cooper C, Cole ZA, Holroyd CR, Earl SC, Harvey NC, Dennison EM, et al. Secular trends in the incidence of hip and other osteoporotic fractures. Osteoporos Int 2011;22:1277-88.

[19] Dhanwal DK, Cooper C, Dennison EM. Geographic variation in osteoporotic hip fracture incidence: the growing importance of Asian influences in coming decades. J Osteoporos 2010, http://dx.doi.org/10.4061/2010/757102.

[20] Dhanwal DK, Dennison EM, Harvey NC, Cooper C. Epidemiology of hip fracture: worldwide geographic variation. Indian J Orthop 2011;45:15-22. 
[21] Xia WB, He SL, Xu L, Liu AM, Jiang Y, Li M, et al. Rapidly increasing rates of hip fracture in Beijing, China. J Bone Miner Res 2011, http://dx.doi.org/10.1002/jbmr.519.

[22] Johnell O, Kanis JA, Jonsson B, Oden A, Johansson H, De Laet C. The burden of hospitalised fractures in Sweden. Osteoporos Int 2005;16:222-8.

[23] Orwig DL, Chan J, Magaziner J. Hip fracture and its consequences: differences between men and women. Orthop Clin North Am 2006;37:611-22.

[24] Melton III LJ, Kearns AE, Atkinson EJ, Bolander ME, Achenbach SJ, Huddleston JM, et al. Secular trends in hip fracture incidence and recurrence. Osteoporos Int 2009;20:687-94

[25] Hagino H, Sakamoto K, Harada A, Nakamura T, Mutoh Y, Mori S, et al. Nationwide one-decade survey of hip fractures in Japan. J Orthop Sci 2010;15:737-45.

[26] Johansson H, Clark P, Carlos F, Oden A, McCloskey EV, Kanis JA. Increasing age- and sex-specific rates of hip fracture in Mexico: a survey of the Mexican institute of social security. Osteoporos Int 2011;22:2359-64.

[27] Kanis JA, Melton III LJ, Christiansen C, Johnston CC, Khaltaev N. The diagnosis of osteoporosis. J Bone Miner Res 1994;9:1137-41.

[28] Kanis JA, McCloskey EV, Johansson H, Oden A, Melton LJ, Khaltaev N. A reference standard for the description of osteoporosis. Bone 2008;42:467-75.

[29] Looker AC, Wahner HW, Dunn WL, Calvo MS, Harris TB, Heyse SP, et al. Updated data on proximal femur bone mineral levels of US adults. Osteoporos Int 1998;8:468-89.

[30] Kanis JA, Johnell O, Oden A, De Laet C, Mellstrom D. Diagnosis of osteoporosis and fracture threshold in men. Calcif Tissue Int 2001:69:218-21.

[31] Selby PL, Davies M, Adams JE. Do men and women fracture bones at similar bone densities? Osteoporos Int 2000;11:153-7.

[32] Orwoll E. Assessing bone density in men. J Bone Miner Res 2000;15:1867-70.

[33] Nguyen T, Sambrook P, Kelly P, Jones G, Lord S, Freund J, et al. Prediction of osteoporotic fractures by postural instability and bone density. BMJ 1993;307:1111-5.

[34] Melton III LJ, Atkinson EJ, O'Connor MK, O'Fallon WM, Riggs BL. Bone density and fracture risk in men. J Bone Miner Res 1998:13:1915-23.

[35] Lunt M, Felsenberg D, Reeve J, Benevolenskaya L, Cannata J, Dequeker J, et al. Bone density variation and its effects on risk of vertebral deformity in men and women studied in thirteen European centers: the EVOS Study. J Bone Miner Res 1997;12:1883-94.

[36] Cummings SR, Cawthon PM, Ensrud KE, Cauley JA, Fink HA, Orwoll ES. BMD and risk of hip and nonvertebral fractures in older men: a prospective study and comparison with older women. J Bone Miner Res 2006;21:1550-6.

[37] De Laet CE, van Hout BA, Burger H, Hofman A, Pols HA. Bone density and risk of hip fracture in men and women: cross sectional analysis. BMJ 1997;315(7102):221-5.

[38] De Laet CE, Van Hout BA, Burger H, Weel AE, Hofman A, Pols HA. Hip fracture prediction in elderly men and women: validation in the Rotterdam study. J Bone Miner Res 1998;13(10):1587-93.

[39] Wasnich RD, Davis JW, Ross PD. Spine fracture risk is predicted by non-spine fractures. Osteoporos Int 1994:4:1-5.

[40] Lewis CE, Ewing SK, Taylor BC, Shikany JM, Fink HA, Ensrud KE, et al. Predictors of non-spine fracture in elderly men: the MrOS study. J Bone Miner Res 2007;22: 211-9.

[41] Fink H, Litwack-Harrison S, Ensrud K, Orwoll E, Bauer D. What is the value of laboratory testing to identify possible secondary contributors to osteoporosis in older men? Proceedings of the American Society for Bone and Mineral Research (ASBMR), San Diego, CA: USA: 2011. p. S339 [Abstract SU0348].

[42] Luukinen H, Kakonen SM, Pettersson K, Koski K, Laippala P, Lovgren T, et al. Strong prediction of fractures among older adults by the ratio of carboxylated to total serum osteocalcin. J Bone Miner Res 2000;15:2473-8.

[43] Meier C, Nguyen TV, Center JR, Seibel MJ, Eisman JA. Bone resorption and osteoporotic fractures in elderly men: the dubbo osteoporosis epidemiology study. J Bone Miner Res 2005;20:579-87.

[44] Bauer DC, Garnero P, Harrison SL, Cauley JA, Eastell R, Ensrud KE, et al. Biochemical markers of bone turnover, hip bone loss, and fracture in older men: the MrOS study. J Bone Miner Res 2009;24:2032-8.

[45] Szulc P, Montella A, Delmas PD. High bone turnover is associated with accelerated bone loss but not with increased fracture risk in men aged 50 and over: the prospective MINOS study. Ann Rheum Dis 2008;67:1249-55.

[46] Vasikaran S, Eastell R, Bruyere O, Foldes AJ, Garnero P, Griesmacher A, et al. Markers of bone turnover for the prediction of fracture risk and monitoring of osteoporosis treatment: a need for international reference standards. Osteoporos Int 2011;22: 391-420.

[47] Khosla S, Riggs BL, Atkinson EJ, Oberg AL, McDaniel LJ, Holets M, et al. Effects of sex and age on bone microstructure at the ultradistal radius: a population-based noninvasive in vivo assessment. J Bone Miner Res 2006;21:124-31.

[48] Kanis JA, Johnell O, Oden A, Johansson H, McCloskey E. FRAX and the assessment of fracture probability in men and women from the UK. Osteoporos Int 2008:19:385-97.

[49] Kanis JA, McCloskey EV, Johansson H, Strom O, Borgstrom F, Oden A. Case finding for the management of osteoporosis with FRAX-assessment and intervention thresholds for the UK. Osteoporos Int 2008;19:1395-408.

[50] Kanis JA. on behalf of the World Health Organization Scientific Group. Assessment of osteoporosis at the primary health care level. Technical Report. UK: World Health Organization Collaborating Centre for Metabolic Bone Diseases. University of Sheffield; 2008

[51] Royal College of Physicians. Clinical Guidelines for the Prevention and Treatment of Osteoporosis. London, UK: RCP; 1999.

[52] Kanis JA, Oden A, Johnell O, Johansson H, De Laet C, Brown J, et al. The use of clinical risk factors enhances the performance of BMD in the prediction of hip and osteoporotic fractures in men and women. Osteoporos Int 2007;18:1033-46.

[53] Committee for Medicinal Products for Human Use (CHMP). Guideline on the evaluation of medicinal products in the treatment of primary osteoporosis. London, Doc. Ref. CPMP/EWP/552/95 Rev. 2; 2006.
[54] Colman EG. The Food and Drug Administration's Osteoporosis Guidance Document: past, present, and future. J Bone Miner Res 2003;18:1125-8.

[55] Orwoll E, Ettinger M, Weiss S, Miller P, Kendler D, Graham J, et al. Alendronate for the treatment of osteoporosis in men. N Engl J Med 2000;343:604-10.

[56] Black DM, Cummings SR, Karpf DB, Cauley JA, Thompson DE, Nevitt MC, et al. Randomised trial of effect of alendronate on risk of fracture in women with existing vertebral fractures. Fracture Intervention Trial Research Group. Lancet 1996:348:1535-41

[57] Pols HA, Felsenberg D, Hanley DA, Stepan J, Munoz-Torres M, Wilkin TJ, et al. Multinational, placebo-controlled, randomized trial of the effects of alendronate on bone density and fracture risk in postmenopausal women with low bone mass: results of the FOSIT study. Fosamax International Trial Study Group. Osteoporos Int 1999;9:461-8.

[58] Boonen S, Vanderschueren D, Geusens P, Bouillon R. Age-associated endocrine deficiencies as potential determinants of femoral neck (type II) osteoporotic fracture occurrence in elderly men. Int J Androl 1997;20:134-43.

[59] Boonen S, Orwoll ES, Wenderoth D, Stoner KJ, Eusebio R, Delmas PD. Once-weekly risedronate in men with osteoporosis: results of a 2-year, placebo-controlled, double-blind, multicenter study. J Bone Miner Res 2009;24:719-25.

[60] Reginster J, Minne HW, Sorensen OH, Hooper M, Roux C, Brandi ML, et al. Randomized trial of the effects of risedronate on vertebral fractures in women with established postmenopausal osteoporosis. Vertebral Efficacy with Risedronate Therapy (VERT) Study Group. Osteoporos Int 2000;11:83-91.

[61] Ringe JD, Farahmand P, Faber H, Dorst A. Sustained efficacy of risedronate in men with primary and secondary osteoporosis: results of a 2-year study. Rheumatol Int 2009:29:311-5.

[62] Lyles KW, Colon-Emeric CS, Magaziner JS, Adachi JD, Pieper CF, Mautalen C, et al. Zoledronic acid and clinical fractures and mortality after hip fracture. N Engl J Med 2007;357:1799-809.

[63] Boonen S, Orwoll E, Magaziner J, Colon-Emeric CS, Adachi JD, Bucci-Rechtweg C, et al. Once-yearly zoledronic acid in older men compared with women with recent hip fracture. J Am Geriatr Soc 2011;59:2084-90.

[64] Orwoll ES, Miller PD, Adachi JD, Brown J, Adler RA, Kendler D, et al. Efficacy and safety of a once-yearly i.v. infusion of zoledronic acid $5 \mathrm{mg}$ versus a once-weekly 70-mg oral alendronate in the treatment of male osteoporosis: a randomized, multicenter, double-blind, active-controlled study. J Bone Miner Res 2010;25:2239-50.

[65] Boonen s, Reginster J-Y, Kaufman J-M, Lippuner K, Zanchetta J, Langdahl B, et al. Fracture risk and zoledronic acid therapy in men with osteoporosis. $\mathrm{N}$ Engl J Med 2012:367:1714-23

[66] Black DM, Delmas PD, Eastell R, Reid IR, Boonen S, Cauley JA, et al. Once-yearly zoledronic acid for treatment of postmenopausal osteoporosis. N Engl J Med 2007:356:1809-22

[67] Reeve J, Meunier PJ, Parsons JA, Bernat M, Bijvoet OL, Courpron P, et al. Anabolic effect of human parathyroid hormone fragment on trabecular bone in involutional osteoporosis: a multicentre trial. Br Med J 1980;280:1340-4.

[68] Slovik DM, Rosenthal DI, Doppelt SH, Potts Jr JT, Daly MA, Campbell JA, et al. Restoration of spinal bone in osteoporotic men by treatment with human parathyroid hormone (1-34) and 1,25-dihydroxyvitamin D. J Bone Miner Res 1986;1: $377-81$

[69] Orwoll ES, Scheele WH, Paul S, Adami S, Syversen U, Diez-Perez A, et al. The effect of teriparatide [human parathyroid hormone (1-34)] therapy on bone density in men with osteoporosis. J Bone Miner Res 2003;18:9-17.

[70] Tashjian Jr AH, Chabner BA. Commentary on clinical safety of recombinant human parathyroid hormone $1-34$ in the treatment of osteoporosis in men and postmenopausal women. J Bone Miner Res 2002;17:1151-61.

[71] Neer RM, Arnaud CD, Zanchetta JR, Prince R, Gaich GA, Reginster JY, et al. Effect of parathyroid hormone (1-34) on fractures and bone mineral density in postmenopausal women with osteoporosis. N Engl J Med 2001;344:1434-41.

[72] Kaufman JM, Orwoll E, Goemaere S, San Martin J, Hossain A, Dalsky GP, et al. Teriparatide effects on vertebral fractures and bone mineral density in men with osteoporosis: treatment and discontinuation of therapy. Osteoporos Int 2005;16:510-6.

[73] Lindsay R, Scheele WH, Neer R, Pohl G, Adami S, Mautalen C, et al. Sustained vertebral fracture risk reduction after withdrawal of teriparatide in postmenopausal women with osteoporosis. Arch Intern Med 2004;164:2024-30.

[74] Leder BZ, Neer RM, Wyland JJ, Lee HW, Burnett-Bowie SM, Finkelstein JS. Effects of teriparatide treatment and discontinuation in postmenopausal women and eugonadal men with osteoporosis. J Clin Endocrinol Metab 2009;94:2915-21.

[75] Black DM, Bilezikian JP, Ensrud KE, Greenspan SL, Palermo L, Hue T, et al. One year of alendronate after one year of parathyroid hormone (1-84) for osteoporosis. N Engl J Med 2005;353:555-65.

[76] Black DM, Schwartz AV, Ensrud KE, Cauley JA, Levis S, Quandt SA, et al. Effects of continuing or stopping alendronate after 5 years of treatment: the Fracture Intervention Trial Long-term Extension (FLEX): a randomized trial. JAMA 2006:296:2927-38

[77] Ensrud KE, Barrett-Connor EL, Schwartz A, Santora AC, Bauer DC, Suryawanshi S, et al. Randomized trial of effect of alendronate continuation versus discontinuation in women with low BMD: results from the Fracture Intervention Trial long-term extension. J Bone Miner Res 2004;19:1259-69.

[78] Wong M, Wan X, Ruff V, Krohn K, Taylor K. Gender differences for initiating teriparatide therapy: baseline data from the Direct Assessment of Nonvertebral Fracture in the Community Experience (DANCE) study. Osteoporos Int 2011, http://dx.doi.org/10.1007/s00198-011-1725-8

[79] Finkelstein JS, Hayes A, Hunzelman JL, Wyland JJ, Lee H, Neer RM. The effects of parathyroid hormone, alendronate, or both in men with osteoporosis. N Engl J Med 2003;349:1216-26 
[80] Finkelstein JS, Leder BZ, Burnett SM, Wyland JJ, Lee H, de la Paz AV, et al. Effects of teriparatide, alendronate, or both on bone turnover in osteoporotic men. J Clin Endocrinol Metab 2006;91:2882-7.

[81] Black DM, Greenspan SL, Ensrud KE, Palermo L, McGowan JA, Lang TF, et al. The effects of parathyroid hormone and alendronate alone or in combination in postmenopausal osteoporosis. N Engl J Med 2003;349:1207-15.

[82] Cosman F, Eriksen EF, Recknor C, Miller PD, Guanabens N, Kasperk C, et al. Effects of intravenous zoledronic acid plus subcutaneous teriparatide [rhPTH(1-34)] in postmenopausal osteoporosis. J Bone Miner Res 2011;26:503-11.

[83] Smith MR. Androgen deprivation therapy for prostate cancer: new concepts and concerns. Curr Opin Endocrinol Diabetes Obes 2007;14:247-54.

[84] Smith MR, Egerdie B, Hernandez Toriz N, Feldman R, Tammela TL, Saad F, et al. Denosumab in men receiving androgen-deprivation therapy for prostate cancer. N Engl J Med 2009;361:745-55.

[85] Amin S, Zhang Y, Sawin CT, Evans SR, Hannan MT, Kiel DP, et al. Association of hypogonadism and estradiol levels with bone mineral density in elderly men from the Framingham study. Ann Intern Med 2000;133:951-63.

[86] Van Pottelbergh I, Goemaere S, Kaufman JM. Bioavailable estradiol and an aromatase gene polymorphism are determinants of bone mineral density changes in men over 70 years of age. J Clin Endocrinol Metab 2003;88:3075-81.

[87] Amin S, Zhang Y, Felson DT, Sawin CT, Hannan MT, Wilson PW, et al. Estradiol, testosterone, and the risk for hip fractures in elderly men from the Framingham Study. Am J Med 2006;119:426-33.

[88] Mellstrom D, Vandenput L, Mallmin H, Holmberg AH, Lorentzon M, Oden A, et al. Older men with low serum estradiol and high serum SHBG have an increased risk of fractures. J Bone Miner Res 2008;23:1552-60.

[89] Doran PM, Riggs BL, Atkinson EJ, Khosla S. Effects of raloxifene, a selective estrogen receptor modulator, on bone turnover markers and serum sex steroid and lipid levels in elderly men. J Bone Miner Res 2001;16:2118-25.

[90] Uebelhart B, Herrmann F, Pavo I, Draper MW, Rizzoli R. Raloxifene treatment is associated with increased serum estradiol and decreased bone remodeling in healthy middle-aged men with low sex hormone levels. J Bone Miner Res 2004;19: 1518-24.

[91] Smith MR, Fallon MA, Lee H, Finkelstein JS. Raloxifene to prevent gonadotropinreleasing hormone agonist-induced bone loss in men with prostate cancer: a randomized controlled trial. J Clin Endocrinol Metab 2004;89:3841-6.

[92] Rachner TD, Khosla S, Hofbauer LC. Osteoporosis: now and the future. Lancet 2011;377:1276-87.

[93] Cummings SR, San Martin J, McClung MR, Siris ES, Eastell R, Reid IR, et al. Denosumab for prevention of fractures in postmenopausal women with osteoporosis. N Engl J Med 2009;361:756-65.

[94] Orwoll ES, Stubbe Teglbjærg C, Chapurlat R, Czerwinski E, Kendler DL, Reginster $\mathrm{J}-\mathrm{Y}$, et al. A phase 3 study of the efficacy and safety of denosumab in men with low bone mineral density: design of the ADAMO trial. Proceedings of the 33rd American Society for Bone and Mineral Research (ASBMR), San Diego, CA, 26. USA J Bone Miner Res; 2011. p. S511 [Abstract MO0442].

[95] Meunier PJ, Roux C, Seeman E, Ortolani S, Badurski JE, Spector TD, et al. The effects of strontium ranelate on the risk of vertebral fracture in women with postmenopausal osteoporosis. N Engl J Med 2004;350:459-68.

[96] Reginster JY, Seeman E, De Vernejoul MC, Adami S, Compston J, Phenekos C, et al. Strontium ranelate reduces the risk of nonvertebral fractures in postmenopausal women with osteoporosis: Treatment of Peripheral Osteoporosis (TROPOS) study. J Clin Endocrinol Metab 2005;90:2816-22.

[97] Kaufman J-M, Ringe J-D, Felsenberg D, Audran M, Bianchi G, Boonen S, et al. Efficacy and safety of strontium ranelate in the treatment of male osteoporosis. Proceedings of the European Congress on Osteoporosis \& Osteoarthritis (ECCEO11-IOF), Valencia Spain Osteoporos Int 201; Abstract OC41: 2011.

[98] Ringe JD, Dorst A, Farahmand P. Efficacy of strontium ranelate on bone mineral density in men with osteoporosis. Arzneimittelforschung 2010:60:267-72.

[99] Bone HG, McClung MR, Roux C, Recker RR, Eisman JA, Verbruggen N, et al. Odanacatib, a cathepsin-K inhibitor for osteoporosis: a two-year study in postmenopausal women with low bone density. J Bone Miner Res 2010;25:937-47.

[100] Eisman JA, Bone HG, Hosking DJ, McClung MR, Reid IR, Rizzoli R, et al. Odanacatib in the treatment of postmenopausal women with low bone mineral density: three-year continued therapy and resolution of effect. J Bone Miner Res 2011;26: 242-51.

[101] Moester MJ, Papapoulos SE, Lowik CW, van Bezooijen RL. Sclerostin: current knowledge and future perspectives. Calcif Tissue Int 2010;87:99-107.

[102] Li X, Ominsky MS, Niu QT, Sun N, Daugherty B, D'Agostin D, et al. Targeted deletion of the sclerostin gene in mice results in increased bone formation and bone strength. J Bone Miner Res 2008;23:860-9.

[103] Padhi D, Jang G, Stouch B, Fang L, Posvar E. Single-dose, placebo-controlled, randomized study of AMG 785, a sclerostin monoclonal antibody. J Bone Miner Res 2010;26:19-26.

[104] Fitzpatrick L, Dabrowski C, Cicconetti G, Papapoulos S, Bone H, Bilezikian J. Ronacaleret, a calcium-sensing receptor antagonist: results of a 1 year double-blind, placebo-controlled, dose-ranging phase II study. Proceedings of the 31st American Society for Bone and Mineral Research (ASBMR), Denver, CO, 24 (S1). USA J Bone Miner Res; 2009. p. S40 [Abstract 1130].

[105] Fukumoto S, Nakamura T, Nishizawa Y, Hayashi M, Matsumoto T, Randomized, single-blinded placebo-controlled study of a novel calcilytic, JTT-305, in patients with postmenopausal osteoporosis. Proceedings of the 31st American Society for Bone and Mineral Research (ASBMR), Denver, CO, 24 (S1). USA J Bone Miner Res; 2009. p. S40 [Abstract 1131].

[106] Baron R, Rawadi G. Targeting the Wnt/beta-catenin pathway to regulate bone formation in the adult skeleton. Endocrinology 2007;148:2635-43.

[107] Canalis E, Giustina A, Bilezikian JP. Mechanisms of anabolic therapies for osteoporosis. N Engl J Med 2007;357:905-16.

[108] Kansara M, Tsang M, Kodjabachian L, Sims NA, Trivett MK, Ehrich M, et al. Wn inhibitory factor 1 is epigenetically silenced in human osteosarcoma, and targeted disruption accelerates osteosarcomagenesis in mice. J Clin Invest 2009; 119:837-51

[109] Gao W, Reiser PJ, Coss CC, Phelps MA, Kearbey JD, Miller DD, et al. Selective androgen receptor modulator treatment improves muscle strength and body composition and prevents bone loss in orchidectomized rats. Endocrinology 2005; 146 : 4887-97.

[110] Yarrow JF, Conover CF, McCoy SC, Lipinska JA, Santillana CA, Hance JM, et al. 17beta-Hydroxyestra-4,9,11-trien-3-one (trenbolone) exhibits tissue selective anabolic activity: effects on muscle, bone, adiposity, hemoglobin, and prostate. Am J Physiol Endocrinol Metab 2011;300:E650-60.

[111] World Health Organization. Guidelines for preclinical evaluation and clinical trials in osteoporosis. Geneva, Switzerland: WHO; 1998. 